\title{
A mulher Submetida à Mastectomia: Tecendo Possibilidades do Cuidar em Enfermagem Considerando o Apoio da Rede Social Primária
}

\author{
A Woman Submitted to Mastectomy: Framing Possibilities of Nursing Care \\ Considering the Support of the Primary Social Net \\ La Mujer se Sometió a una Mastectomía: Posibilidades de Tejido de la Atención \\ en Enfermería Teniendo en Cuenta la Red de Apoyo Social Primaria
}

\author{
Jaqueline Ferreira Ventura Bittencourt', Ivis Emília de Oliveira Souza ${ }^{2}$, Teresa Caldas Camargo ${ }^{3}$, Maria de Fátima Batalha de Menezes ${ }^{4}$
}

\begin{abstract}
Resumo
A família desempenha um papel importante diante do diagnóstico de doença oncológica. A assistência de enfermagem voltada para a mulher submetida à mastectomia numa perspectiva de humanização precisa valorizar sua rede de relacionamento interpessoal. Nesta pesquisa buscou-se alcançar os objetivos de: descrever a rede social primária da mulher submetida à mastectomia; analisar o tipo de apoio que a rede social primária oferece; discutir possibilidades assistenciais para essa mulher considerando as relaçôes que estabelece com sua rede social primária. Utilizou-se a abordagem teórico-metodológica de Lia Sanicola. O cenário da produção dos dados foi o Hospital do Câncer III do Instituto Nacional de Câncer. Realizaram-se 13 entrevistas que permitiram a construção dos mapas de rede social correspondentes. A análise compreensiva produziu as categorias analíticas: 1. Ajuda cotidiana para cuidados como curativo, controle do dreno, banho e troca de roupas, além de auxílio nos afazeres domésticos e no transporte. 2. Apoio emocional/afetivo mediante a disponibilidade para acompanhamento ao hospital durante o tratamento e para encarar o diagnóstico e prosseguir com o tratamento até o fim. 3. Ajuda na emergência ao precisar de acomodação temporária na casa de familiares/parentes para dar continuidade ao tratamento. 4. Conselho/informaçáo mediante a indicação da melhor instituição e da atenção com os agendamentos, retornos, exames e orientaçóes no pós-operatório. Concluíu-se que, para o profissional de saúde, o conhecimento dos condicionantes relacionais e/ou sociais podem se constituir em formas inovadoras de cuidar no sentido de reconhecer o acompanhante familiar como elemento coadjuvante na recuperação da condição de saúde da mulher submetida à mastectomia.
\end{abstract}

Palavras-chave: Mastectomia; Saúde da Mulher; Enfermagem

Tese apresentada ao Programa de Pós-Graduaçâo e Pesquisa da Escola de Enfermagem Anna Nery da Universidade Federal do Rio de Janeiro (EEAN/UFRJ) para obtençấo do título de Doutor em Enfermagem.

${ }^{1}$ Autora. Doutora em Enfermagem. Professora da EEAN/UFRJ. Rio de Janeiro (RJ), Brasil.

${ }^{2}$ Coautora. Orientadora da Tese. Doutora em Enfermagem. Professora Titular de Enfermagem Obstétrica do Departamento de Enfermagem Materno Infantil da Escola de EEAN/UFRJ. Rio de Janeiro (RJ), Brasil.

${ }^{3}$ Coautora. Enfermeira. Doutora em Enfermagem. Editora Científica da Revista Brasileira de Cancerologia do Instituto Nacional de Câncer (INCA). Rio de Janeiro (RJ), Brasil.

${ }^{4}$ Coautora. Doutora em Enfermagem. Enfermeira Coordenadora da Educação Continuada da Divisão de Enfermagem do Hospital do Câncer I (HCI) / INCA.

Endereço para Correspondência: Jaqueline Ferreira Ventura Bittencourt. Rua Afonso Cavalcanti, 275 - Cidade Nova. Rio de Janeiro (RJ), Brasil. CEP: 20211-110.E-mail: jaquelinebittencourt@oi.com.br 